\title{
DESIGN AND EVALUATION OF GUANFACINE EXTENDED RELEASE FORMULATION
}

\section{*SANJEEVANI DESAI ${ }^{1}$, DURGACHARAN BHAGWAT ${ }^{2}$, SUNITA SHINDE' ${ }^{1}$,OHN DISOUZA ${ }^{1}$}

1Tatyasaheb Kore College of Pharmacy, Warananagar, 416113, Maharashtra, India. Bharati Vidyapeeth College of Pharmacy, Kolhapur, Maharashtra, India.

Email: srdesai.tkcp@gmail.com

Received: 31 Oct 2018, Revised and Accepted: 30 Jan 2019

\section{ABSTRACT}

Objective: The present study was aimed to develop of the Guanfacine Hydrochloride Extended-release tablets for the treatment of Attention Deficit Hyperactivity Disorder (ADHD). The dosage regimen of Guanfacine Hydrochloride is $4 \mathrm{mg}$ at every $6 \mathrm{~h}$. The concentration of Guanfacine in plasma is fluctuating. Hence, to control the plasma fluctuation and to avoid toxicity problem, Guanfacine Hydrochloride was chosen as a drug with an aim to develop an extended release system for 20 to $24 \mathrm{~h}$.

Methods: The design of the system was based on the use of pH-dependent polymer (Hydroxypropyl Methyl Cellulose), pH-independent polymer (Eudragit L 100-55), along with microenvironment modifiers such as organic acid (Fumaric acid) were used in the formulation. Drug-excipient compatibility was studied by FTIR. Before compression, the granules were evaluated for precompression parameters such as bulk density, tapped density, an angle of repose, compressibility index and Hausner's ratio. After compression, evaluation tests of tablets such as general appearance, hardness, thickness, weight variation, friability, content uniformity, in vitro release studies and stability studies were performed.

Results: Out of 9 formulations, the drug release was found to be within the innovator formulation F9. The stability study of formulation F9 revealed there was no significant change in physical and chemical properties of drug stored at $40{ }^{\circ} \mathrm{C} / 75 \% \mathrm{RH}, 30{ }^{\circ} \mathrm{C} / 65 \% \mathrm{RH}, 25{ }^{\circ} \mathrm{C} / 60 \% \mathrm{RH}$ for $2 \mathrm{mo}$.

Conclusion: Optimized formulation batch F9 showed highest F2 value which indicates similarity with innovator product. The study indicates that Guanfacine Hydrochloride Extended-release tablet was successfully developed.

Keywords: Extended-release, Solubility, pH-dependent polymer, In vitro study

(C) 2019 The Authors. Published by Innovare Academic Sciences Pvt Ltd. This is an open-access article under the CC BY license (http://creativecommons.org/licenses/by/4.0/D DOI: http://dx.doi.org/10.22159/ijap.2019v11i3.30578

\section{INTRODUCTION}

Oral drug delivery has been known for decades as the most widely utilized route of administration for delivery of drugs via different dosage forms due to its ease of administration, high patient compliance and flexibility in the design of dosage form. The goal of any drug delivery system is to provide a therapeutic amount of drug to proper site in the body to achieve promptly and then maintain, the desired drug concentration. The design of a proper dosage regimen is an important element in accomplishing this goal [1, 2].

Conventional oral drug delivery systems are slowly fading away in the market owing to disadvantages. These delivery systems produce fluctuation of drug plasma level that either exists at a safe therapeutic level or quickly falls below the minimum effective level. This effect is usually totally dependent on the particular agent's biological half-life, the frequency of administration and release rate. It is recognized that many patients can benefit from drugs intended for chronic administration by maintaining the plasma level within a safe effective range [3]. Extended oral drug delivery systems are highly recognized today for their benefits, improving the disadvantages of conventional drug delivery systems.

To be a successful, extended-release [ER] products the drug must be released from the dosage from at a predetermined rate in gastrointestinal fluids, maintain sufficient gastrointestinal residence time and be absorbed at a rate that will replace the amount of drug being metabolized and excreted. Extended drug delivery systems are used in the treatment of chronic rather than the acute condition, and they process a good margin of safety [4-6].

While psychostimulant medications have large effect sizes for treatment of attention-deficit/hyperactivity disorder (ADHD) symptoms. Guanfacine is a selective alpha2-agonist that shares some pharmacological properties with the non-selective alpha2-agonist clonidine [7].

The aim of this research work was to formulate guanfacine hydrochloride ( $\mathrm{HCl})$ ER tablet which delivered drug for $24 \mathrm{~h}$.

\section{MATERIALS AND METHODS}

\section{Materials}

Guanfacine $\mathrm{HCl}$ was supplied by Intas Pharmaceutical. H. P. M. C, Methacrylic Acid (Eudragit L100-55), Microcrystalline Cellulose PH102, Lactose Monohydrate, Fumaric Acid, Glyceryl Behenate, Lake Of Indigo Carmine, Ferric Oxide Yellow from Evonik Signet Chemical Corporation Pvt. Ltd. Industries, Mumbai. All other chemicals used were of analytical grade.

\section{Methods}

Preformulation study

Organoleptic properties

The drug samples were evaluated for its colour, odour, taste and appearance. The result was mentioned in table 3 .

\section{Melting point}

The melting point was determined by the melting point apparatus. The temperature at which drug melted was recorded the result was mentioned in table 3.

\section{Solubility}

For the determination of solubility, an excess amount of drug was added in the solvent (water, $0.1 \mathrm{~N} \mathrm{HCl}$, Acetate buffer $\mathrm{pH} 4.5$, Phosphate Buffer $\mathrm{pH}$ 6.8) at room temperature and kept for $48 \mathrm{~h}$ with occasional shaking. The supernatant was taken and analyzed by using Shimadzu UV 1800 double beam spectrophotometer. The results were mentioned in table 4 .

\section{Differential scanning calorimetry (DSC)}

The DSC study was carried out for the obtained sample of guanfacine $\mathrm{HCl}$ to confirm its purity. The DSC patterns were recorded on a METTLER TOLEDO STARe System. $1.5 \mathrm{mg}$ of drug was heated in crimped aluminium pans at a scanning rate of $400{ }^{\circ} \mathrm{C} / \mathrm{min}$ in an atmosphere of nitrogen gas flow $40 \mathrm{ml} / \mathrm{min}$ using the range of 40 $350^{\circ} \mathrm{C}$. The DSC curve was shown in fig. 1 . 


\section{Formulation development}

The primary aim of this development work was to produce a stable and bioequivalent formulation as compare to that of reference formulation. The formulation development work was undertaken considering the following approaches [8-11].

\section{Direct compression}

The range of concentration of release modifier was also based on the patent of the innovator's product. i.e. Concentration of hydroxypropyl methylcellulose (HPMC) as shown in the following table.

Table 1: Batch formula

\begin{tabular}{|c|c|c|c|c|c|c|c|c|c|c|}
\hline \multirow[t]{2}{*}{ S. No. } & \multirow[t]{2}{*}{ Ingredients } & \multicolumn{9}{|c|}{ Batch codes (Quantity in mg/tab) } \\
\hline & & F1 & F2 & F3 & F4 & F5 & F6 & F7 & F8 & F9 \\
\hline 1. & Guanfacine $\mathrm{HCl}$ & 4.59 & 4.59 & 4.59 & 4.59 & 4.59 & 4.59 & 4.59 & 4.59 & 4.59 \\
\hline 2. & Microcrystalline cellulose & 50 & 82 & 38.21 & 38.21 & 47.21 & 47.21 & 41.21 & 75.21 & 41.2 \\
\hline 3. & Methacrylic acid & 60 & 40 & 60 & 60 & 65 & 70 & 70 & 70 & 70 \\
\hline 4. & HPMC & 49 & 55 & 60 & 60 & 35 & 30 & 30 & 30 & 30 \\
\hline 5. & Lactose monohydrate & 52.20 & 52.20 & 57 & 57 & 49 & 49 & - & - & - \\
\hline 6. & Lake of Indigo Carmine & 0.6 & 0.6 & 0.6 & 0.6 & 0.6 & 0.6 & 0.6 & 0.6 & 0.6 \\
\hline 7. & Ferric oxide yellow & 0.6 & 0.6 & 0.6 & 0.6 & 0.6 & 0.6 & 0.6 & 0.6 & 0.6 \\
\hline 8. & Fumaric acid & 10 & 12 & 13 & 13 & 18 & 18 & - & 18 & 18 \\
\hline 9. & Glyceryl behenate & 36 & 20 & 26 & 26 & 40 & 40 & 40 & 26 & 40 \\
\hline 10. & Ludipress & - & - & - & - & - & - & 60 & 50 & 40 \\
\hline
\end{tabular}

\section{Compatibility study of drugs with Excipients FTIR}

FTIR spectra of pure drug and conventional and ready base approach formulations of these excipients with the drug were recorded on Agilent FTIR spectrophotometer. The instrument was operated under dry air purge and the scans were collected with a resolution of $4 \mathrm{~cm}^{-1}$ over the region $4000-650 \mathrm{~cm}^{-1}$.

\section{Evaluation of granules}

\section{Bulk density}

Bulk Density is the ratio of the weight of powder to the volume it occupies. It is expressed as $\mathrm{g} / \mathrm{ml}$.

\section{Flow property}

Compressibility is indirectly related to the relative flow rate, cohesiveness and particle size distribution of the powder. Tapped and untapped bulk density measurements can estimate the compressibility of a material

\section{Selection of dissolution media}

Dissolution media was selected based on the dissolution database published in literature available and based on the solubility and stability of the dosage form and considering the intended use of the dosage form. The HCl Buffer $\mathrm{pH} 2.2$, Acetate Buffer $\mathrm{pH}$ 4.5, Phosphate Buffer pH 6.8 media were selected for dissolution profile.

\section{Characterization of an innovator product}

\section{Physical characterization}

The reference product for guanfacine $\mathrm{HCl}$ is INTUNIV Tablets manufactured by Shire Inc. The developmental work was done considering innovator product i.e. INTUNIV $4 \mathrm{mg}$ Tablets. The physical characteristics of the INTUNIV $4 \mathrm{mg}$ Tablets are given in.

Table 2: Product details of intuniv $4 \mathrm{mg}$

\begin{tabular}{lll}
\hline S. No. & Description & Intuniv 4 mg tablet \\
\hline 1 & Name of Product & Intuniv Tablets $4 \mathrm{mg}$ \\
2 & Label Claim & Contains Guanfacine HCl eq. to 4 mg of Guanfacine \\
4 & Manufactured By & Shire US Inc, Wayne, PA 19087, Made in USA \\
5 & Market & US \\
6 & Dosage form details & \\
6.1 & Dosage form & ER Tablet \\
6.2 & Shape & Capsule-shaped, Biconvax \\
6.3 & Color & Green \\
6.4 & Size (Length XWidth) & $4.31 \mathrm{X} \mathrm{6.10 \textrm {mm }}$ \\
6.5 & Thickness & $268 \mathrm{mg}$ \\
6.6 & Average weight & \\
\hline
\end{tabular}

\section{Comparison of dissolution profiles for selection of optimized batch}

The similarity factor (f2) given by SUPAC guidelines for a modified release dosage form was used as a basis to compare dissolution profiles. The dissolution profiles are considered to be similar when f2 is between 50 and 100. The dissolution profile of products were compared using a 2 which is calculated from the following formula,

$$
f_{2}=50 \times \log \left\{\left[1+\left(\frac{1}{n}\right) \sum_{t=1}^{n} w_{t}\left(R_{t}-T_{t}\right)^{2}\right]^{-0.5} \times 100\right\}
$$

Where $\mathrm{n}$ is the dissolution time and $\mathrm{R}_{t}$ and $\mathrm{T}_{\mathrm{t}}$ are the reference (here is the theoretical dissolution profile of guanfacine $\mathrm{HCl}$ ) and test dissolution value at time t48. All Factorial design batches (F1 to F8) were compared with the theoretical profile for calculation of similarity factor.

\section{Stability study}

The stability study is performed to check the physical-chemical integrity of the product. For performing the stability study storage condition was determined based on ICH Guidelines. The selected F9 batch was subjected to stability study [12-15].

\section{RESULTS AND DISCUSSION}

\section{Preformulation study}

The received samples were identified by various tests. The results are as shown below. 
Table 3: Organoleptic properties of guanfacine $\mathrm{HCl}$

\begin{tabular}{llll}
\hline S. No. & Organoleptic properties & Observations & Specification \\
\hline 1. & Colour & White or off white & White or off white \\
2. & Odour & Odourless & Odourless \\
3. & Description & Crystalline powder & Crystalline powder \\
4. & Melting Point & $226^{\circ} \mathrm{C}$ & $225^{\circ} \mathrm{C}-227^{\circ} \mathrm{C}$ \\
\hline
\end{tabular}

Table 4: Solubility profile of guanfacine $\mathrm{HCl}$

\begin{tabular}{lll}
\hline S. No. & pH solubility profile & Solubility (mg/ml) \\
\hline 1 & Water & 0.163 \\
2 & $0.1 \mathrm{~N} \mathrm{HCl}$ & 0.420 \\
3 & Acetate buffer pH 4.5 & 1.265 \\
4 & Phosphate buffer pH 6.8 & 1.302 \\
\hline
\end{tabular}

Based on Organoleptic properties and solubility studied drug was characterized for the above parameters which were found to be similar and complies with the standard specification. Hence the guanfacine $\mathrm{HCl}$ was identified and considered to be pure.

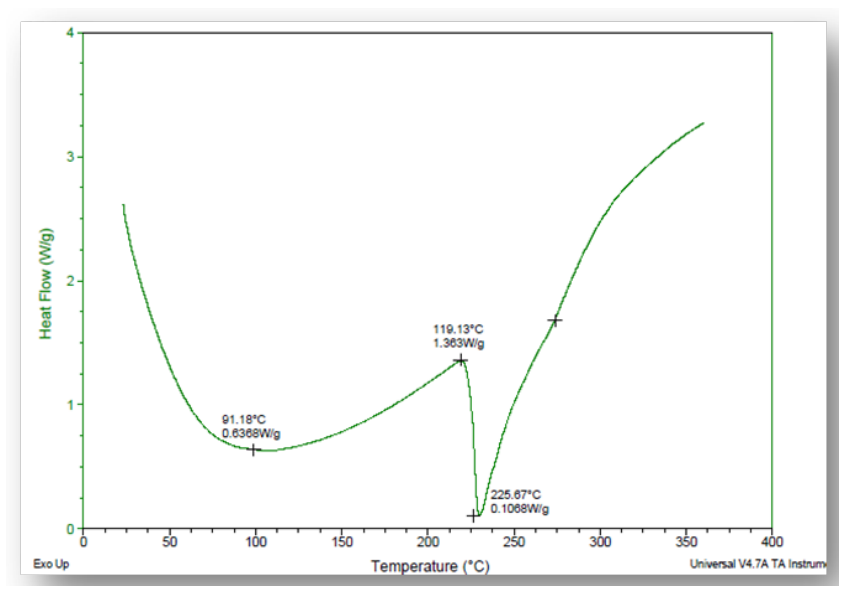

Fig. 1: DSC thermogram of guanfacine $\mathrm{HCl}$

\section{Differential scanning calorimetry (DSC)}

The DSC spectrum of guanfacine $\mathrm{HCl}$ was obtained and is given in fig. 1. Drug shows Sharp melting endotherm at $225^{\circ} \mathrm{C}$, which is the melting point of the drug.

Thermal analysis showed a characteristic sharp endothermic peck at $225.67{ }^{\circ} \mathrm{C}$ indicating the melting point of the drug. The fact confirmed the obtained drug was pure and in crystalline form.

\section{Analytical methods}

UV spectroscopy

Calibration curves of guanfacine $\mathrm{HCl}$ were carried out in different media like methanol, $0.1 \mathrm{~N} \mathrm{HCl}$ and Phosphate buffer $\mathrm{pH} 6.8$

Calibration curve in Methanol, $0.1 \mathrm{~N} \mathrm{HCl}$ and Phosphate buffer $\mathrm{pH} 6.8$ were found to be linear having $\mathrm{R}^{2}$ value $0.9992,0.9907,0.9992$ respectively as shown in fig. 2 .

\section{FTIR compatibility study}

To check the interaction between drug and excipients used in the formulations, FTIR studies were performed.

These peaks were not affected and prominently observed in FTIR spectra given in fig. 3 Thus, we can say that there was no significant interaction between drug and excipients were observed.
Methano1

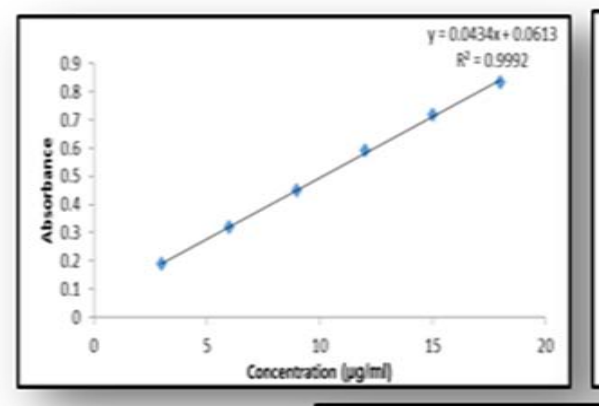

\section{$0.1 \mathrm{~N} \mathrm{HCl}$}
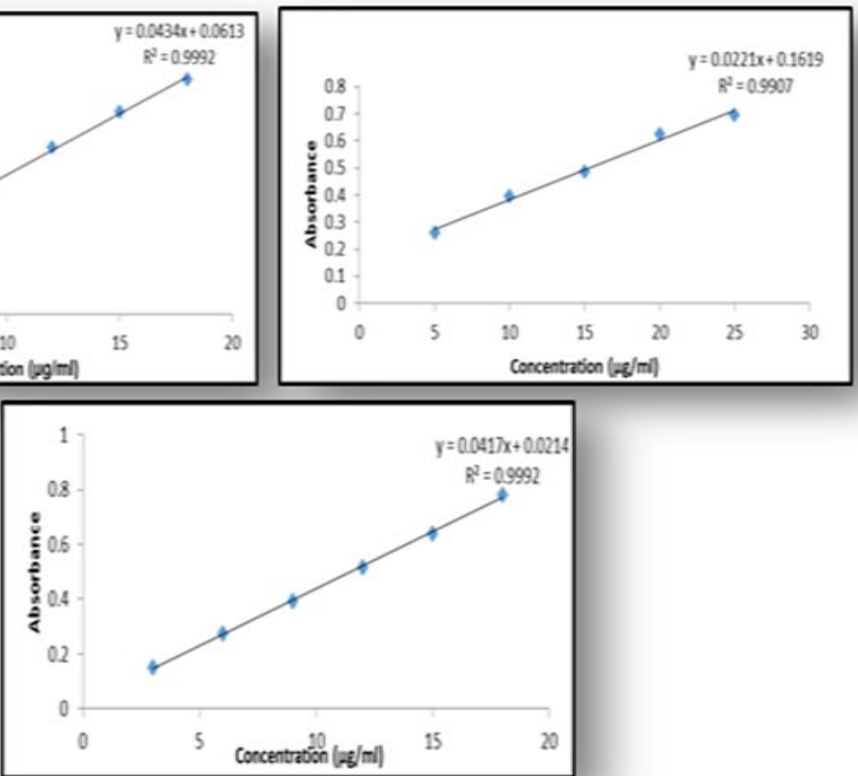

Phosphate buffer $\mathrm{pH} 6.8$

Fig. 2: Calibration curve in Methanol, 0.1N HCl, Phosphate buffer pH 6.8 
Guanfacine HС

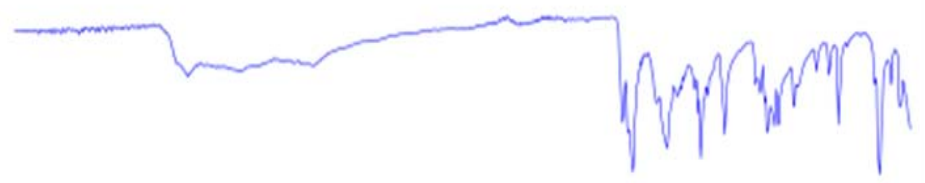

Guanfodine HCL + polymers

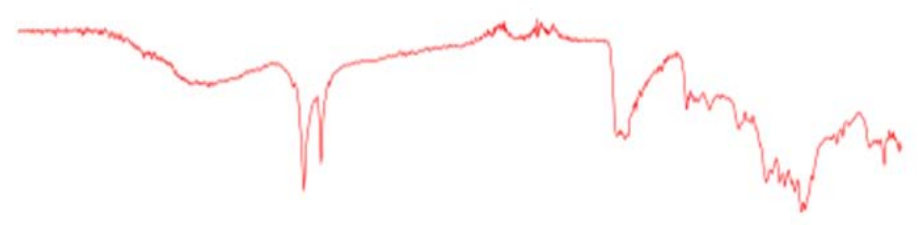

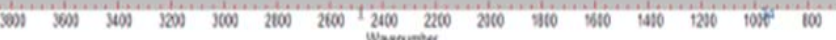

Fig. 3: FTIR spectrum of drug and physical mixture

Table 5: Physical evaluation of granulation batches

\begin{tabular}{|c|c|c|c|c|c|c|c|c|c|}
\hline Batch code & F1 & F2 & F3 & F4 & F5 & F6 & F7 & F8 & F9 \\
\hline Bulk density $(\mathrm{g} / \mathrm{ml})$ & 0.428 & 0.457 & 0.604 & 0.667 & 0.646 & 0.626 & 0.410 & 0.528 & 0.475 \\
\hline Tap density (g/ml) & 0.545 & 0.592 & 0.760 & 0.771 & 0.729 & 0.724 & 0.508 & 0.624 & 0.552 \\
\hline Carr's Index (\%) & 21.46 & 22.80 & 20.54 & 13.48 & 13.02 & 13.52 & 19.29 & 15.31 & 13.92 \\
\hline Hausner's Ratio & 1.27 & 1.29 & 1.25 & 1.15 & 1.12 & 1.15 & 1.23 & 1.18 & 1.16 \\
\hline
\end{tabular}

\section{Evaluation of granules}

Physical Evaluation of granulation batches was indicated in table 5 . The Carr's Index and Hausner's Ratio was indicated blend showed good physical property and did not show any issue regarding weight variation and indicates that direct compression method was suitable.

\section{Formulation development}

\section{Physical characteristics}

Physical characteristics data such as average weight, hardness, thickness, assay, friability were mentioned in table 6 . Results revealed that assay has a more significant effect on the dissolution profile of guanfacine $\mathrm{HCl}$ ER formulation.

Table 6: Physical evaluation of tablet

\begin{tabular}{lllll}
\hline \multicolumn{2}{l}{ Physical parameter } & & & \\
\hline Batches & Average Weight (mg) & Hardness (N) & Thickness (mm) & Friability (\%) \\
\hline F1 & 265 & $10 \pm 6.05$ & $4.30-4.40$ & $0.89 \pm 0.011$ \\
F2 & 265 & $50 \pm 7.8$ & $4.60-4.70$ & $0.65 \pm 0.012$ \\
F3 & 260 & $90 \pm 2.25$ & $4.35-4.45$ & $0.213 \pm 0.018$ \\
F4 & 260 & $110 \pm 2.06$ & $4.45-4.55$ & Nil \\
F5 & 260 & $100 \pm 2.54$ & $4.45-4.55$ & $0.132 \pm 0.018$ \\
F6 & 265 & $110 \pm 3.05$ & $4.20-4.30$ & $0.215 \pm 0.021$ \\
F7 & 267.20 & $100 \pm 6.52$ & 9.82 & $0.220 \pm 0.017$ \\
F8 & 265 & $110 \pm 7.52$ & $4.40-4.50$ & 99 \\
F9 & 265 & $110 \pm 6.22$ & $4.45-4.465$ & 98.5 \\
\hline
\end{tabular}

\section{Dissolution study}

Dissolution Profile of Intuniv tablet $4 \mathrm{mg}$. (innovator) was carried out in a different solvent. Comparative study were carries out between formulated batches F1-F9 and Intuniv tablet. From the above result, it was observed that Intuniv $4 \mathrm{mg}$ tablet showed more release in a phosphate buffer solution having $\mathrm{pH} 6.8$ The above-mentioned results of F1-F9 batch \% cumulative drug released in $6.8 \mathrm{pH}$ phosphate buffer with USP apparatus type II indicates F1-F3 batch showed less released after $24 \mathrm{~h}$ compared to remaining batches. Batch F9 showed good similarity with the innovator product.

\section{Statistical treatment of dissolution data}

The values of similarity factor (f2) for the batch F9 showed maximum $\mathrm{f} 2$ value 85.42 as shown in table 7 .

Hence, formulation batch F9 was considered as an optimum batch. 


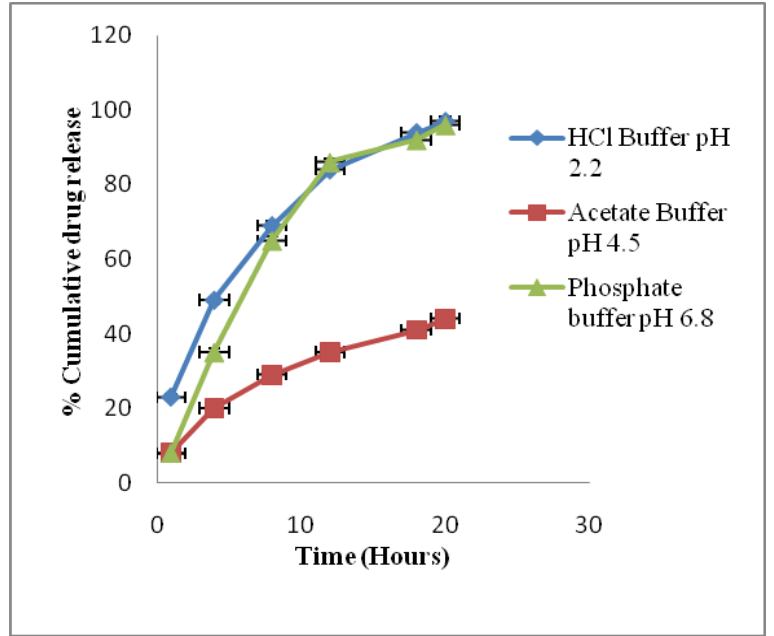

Fig. 4: Dissolution profile of intuniv $4 \mathrm{mg}$ tablet

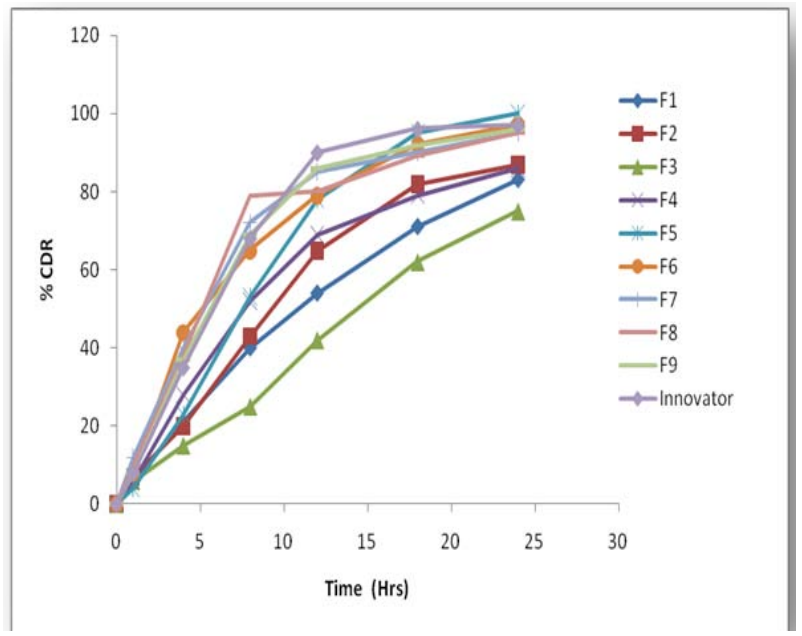

Fig. 5: Dissolution profile of intuniv 4 mg tablets and F1-F9 batch

Table 7: Similarity factor (f2) for F1-F9

\begin{tabular}{llllllllll}
\hline Batch & F1 & F2 & F3 & F4 & F5 & F6 & F7 & F8 & F9 \\
\hline Similarity Factor & 40.5 & 46.75 & 33.1 & 51.02 & 59.37 & 67.97 & 74.24 & 71.87 & 85.42 \\
\hline
\end{tabular}

Table 8: Stability evaluation of optimized batches

\begin{tabular}{|c|c|c|c|c|c|c|c|}
\hline \multirow{3}{*}{$\begin{array}{l}\text { Batch No. } \\
\text { Test }\end{array}$} & \multicolumn{7}{|l|}{ F9 } \\
\hline & \multirow{2}{*}{$\begin{array}{l}\text { Condition } \\
\text { Initial } \\
\end{array}$} & \multicolumn{2}{|c|}{$40{ }^{\circ} \mathrm{C} / 75 \% \mathrm{RH}$} & \multicolumn{2}{|c|}{$30{ }^{\circ} \mathrm{C} / 65 \% \mathrm{RH}$} & \multicolumn{2}{|c|}{$25^{\circ} \mathrm{C} / 60 \% \mathrm{RH}$} \\
\hline & & $1 \mathrm{Mo}$ & 2 Mo & $1 \mathrm{Mo}$ & 2 Mo & $1 \mathrm{Mo}$ & 2 Mo \\
\hline Description & \multicolumn{7}{|c|}{ Light Green Oval Shaped } \\
\hline Assay & $99.5 \%$ & $98.9 \%$ & $99 \%$ & $98.2 \%$ & $99.4 \%$ & $99.3 \%$ & $99.2 \%$ \\
\hline Hardness & $90 \mathrm{~N}$ & $82 \mathrm{~N}$ & $85 \mathrm{~N}$ & $80 \mathrm{~N}$ & $86 \mathrm{~N}$ & $90 \mathrm{~N}$ & $87 \mathrm{~N}$ \\
\hline Avg. Wt. (mg) & 265 & 264.8 & 264.8 & 265 & 265 & 265 & 265 \\
\hline Time (Hrs) & \multicolumn{7}{|c|}{ \% DR in Phosphate 6.8} \\
\hline 1 & 9.21 & 8.56 & 7.98 & 8.41 & 7.64 & 8.47 & 8.1 \\
\hline 4 & 34.42 & 37.52 & 38.24 & 36.45 & 39.14 & 38.42 & 37.2 \\
\hline 8 & 64.22 & 66.41 & 62.45 & 63.25 & 65.12 & 61.45 & 69.75 \\
\hline 12 & 84.65 & 86.14 & 82.14 & 84.12 & 81.85 & 85.45 & 86.58 \\
\hline 18 & 91.56 & 92.45 & 94.12 & 90.12 & 91.46 & 92.84 & 92.56 \\
\hline 24 & 96.14 & 97.12 & 97.52 & 95.6 & 96.42 & 97.46 & 96.12 \\
\hline
\end{tabular}

\section{Stability study}

Stability study of optimized batch F9 was carried out and results as shown in table 8.

The above table shows that there was no considerable changes in appearance, physical parameter and chemical parameters of the formulation after stability study. From observed results, it was stated that the prepared tablet was found to be stable.

\section{CONCLUSION}

The focus of the current study was to develop the extended-release tablet of guanfacine $\mathrm{HCl}$ using a direct compression method. In this developed formulation $\mathrm{pH}$-dependent and $\mathrm{pH}$-independent polymers such as Hydroxy Propyl methylcellulose and Eudragit L100-55 were utilized to prepare matrix tablets.

Incompatibility study IR, it was observed that the drug was in pure form and there were no major interactions with other polymers. The in vitro dissolution study revealed that the batch F9 was best among nine batches been prepared and showed a similar release pattern with innovator product. Stability study of the optimized batch was carried out at $40{ }^{\circ} \mathrm{C} / 75 \% \mathrm{RH}, 30{ }^{\circ} \mathrm{C} / 65 \% \mathrm{RH}, 25{ }^{\circ} \mathrm{C} / 60 \% \mathrm{RH}$. It was found that there was no statistically significant difference in in vitro drug release before and after stability study. Thus, from the above conclusion, it is summarized that the formulation and evaluation of guanfacine $\mathrm{HCl}$ extended-release tablet was successfully prepared by using a direct compression method.

\section{AUTHORS CONTRIBUTIONS}

All the author have contributed equally

\section{CONFLICT OF INTERESTS}

Declared none

\section{REFERENCES}

1. Vova B, Khopade AJ, Jain NK. Targeted oral drug delivery. Indian Drugs 1996;33:365-73.

2. Chiao CL, Robinson JR. In: Remington: the science and practice of pharmacy. $19^{\text {th }}$ Gennaro AR. Ed; Mack Publishing Company; 1995. p. $1660-70$

3. Lachman L, Liberman HA. Theory and practice of industrial pharmacy. $3^{\text {rd }}$ Varghese publishing house: Mumbai; 1990. p. 314-24.

4. Desai SR, Disouza JI, Musle KL, Hosmani AH. Solubility enhancement of ritonavir by hot melt extrusion. Int J Pharm Pharm Sci 2016;8:309-12.

5. Brahmankar DM, Jaiswal SB. Biopharmaceutics and pharmacokinetics a treatise. $1^{\text {st }}$ Delhi: Vallabh Prakashan; 2002. p. 335-71. 
6. Ochoa L, Igartua M. Novel extended release formulation of lovastatin by one-step granulation: in vitro and in vivo evaluation. Eur J Pharm Biopharm 2011;77:306-12.

7. Carla S, Sandra F. Didanosine extended-release matrix tablets: optimization of formulation variables using a statistical experimental design. Int J Pharm 2002;237:107-18.

8. Reddy SE. Formulation and evaluation of sustained release floating tablets of ciprofloxacin with hepatoprotectant. Int J Pharm Appl 2012;3:289-92.

9. Nagarajun R, Rajesh K. Design and evaluation of delayed and extended-release tablets of mesalamine. J Pharm Sci Tech 2010;2:103-10.

10. Desai SR, Disouza JI, Sable AM, Hosmani AH. Development of the orodispersible tablet of atorvastatin calcium using hot melt extrusion. Drug Delivery Lett 2015;5:1-12.
11. Higuchi T. Mechanism of sustained action mediation, theoretical analysis of rate of release of solid drugs dispersed in solid matrices. J Pharm Sci 1963;52:1145-9.

12. Hixon AW, Crowell JH. Dependence of reaction velocity upon surface and agitation. Ind Eng Chem 1931;23:923-31.

13. Desai SR, Disouza JI, Shirwadkar BS. Process validation: an approach for herbal tablet standardization. Int J Pharmacogn Phytochem Res 2016;8:313-20.

14. Korsmeyer RW, Gurny R, Doelker E, Buri P, Peppas NA. Mechanism of solute release from porous hydrophillic polymers. Int J Pharma 1983;15:25-35.

15. Desai SR, Doke AA, Disouza JI. Development and evaluation of antifungal topical niosomal gel formulation. Int J Pharm Pharm Sci 2011;3:224-31. 